\title{
Apropriações de linguagem em cartazes de contestação
}

\section{Language appropriation in protest posters}

\author{
FUKUSHIMA, Kando; Mestre; UTFPR \\ kandof@gmail.com \\ QUELUZ, Marilda Lopes Pinheiro; Doutora; UTFPR \\ pqueluz@gmail.com
}

\section{Resumo}

O presente artigo apresenta e discute a apropriação de referências e linguagens gráficas em cartazes de contestação. $O$ intuito é verificar a recorrência dessa prática em diferentes contextos e comentar sua utilização a partir de estratégias diversas. A abordagem analítica dessa prática busca evidenciar aspectos que extrapolam a imitação de estilos visuais, articulando as referências identificadas com o contexto de produção dos cartazes. O recorte específico em cartazes de contestação permite tornar mais evidente a responsabilidade do design e a negociação de sentidos no âmbito social. Os exemplos escolhidos abrangem temáticas variadas, como políticas bélicas estadunidenses nos anos 1980 e a repressão policial às manifestações públicas no Brasil em 2016.

Palavras Chave: cartaz; apropriação; mobilização social.

\begin{abstract}
This paper presents and discusses issues concerning the appropriation of references and graphic language in protest posters. The aim of it is to reveal the recurrence of such practice in different contexts and comment on their utilization from various different ways. The analytical approach of this practice seeks to point out aspects which surpasses imitations of visual styles, linking the identified references with the production context of these posters. This specific approach in protest posters allows us to make it more evident the responsibility of design and the negotiation of meanings in the social context. The chosen examples cover various themes, such as the North American war policy posters in 1980s and the police repression against public demonstrators in Brazil in 2016.
\end{abstract}

Keywords: poster, appropriation, social mobilization. 


\section{Introdução}

O presente artigo apresenta e discute seis cartazes de contestação, de origens diversas, mas que utilizam um artifício recorrente: além da própria linguagem do cartaz, se apropriam de referências de outros campos da comunicação para construir suas mensagens.

A apropriação é aqui entendida não como simples pastiche de estilos, em seu sentido negativo, mas como recurso incorporado à tradição do design (POYNOR, 2010). Algumas vezes, as referências podem ser diretas, utilizando a reprodução de imagens deslocado de seus contextos originais, e em outras ocasiões, de forma mais elaborada, como citações que expandem as possibilidades de interpretação.

O recorte geográfico e temporal dos exemplos buscam reforçar a ideia de que esta é uma estratégia recorrente e importante para a produção de cartazes de protesto. 0 repertório citado nesses exemplos utilizam a publicidade, o cinema e a música em cartazes de diversos formatos e formas de distribuição. Além de exemplos mais conhecidos e citados em diversas fontes bibliográficas, como o trabalho de Seymour Chwast (Figura 02), serão também apresentados cartazes de autoria desconhecida.

Aqui as referências se tornam desvios, provocações e, em alguns casos, paródias de seus contextos originais. A apropriação se torna um gesto político, seja pelo conteúdo do texto contestatório, seja pela própria crítica à iconografia de seus originais.

\section{Design e cartazes de contestação}

A relação entre os movimentos sociais e o design é constantemente apontada em obras que discutem a história do design. Os cartazes são comumente apresentados como um suporte privilegiado dessa relação (BARNICOAT, 1972; HOLLIS, 2001; MEGGS, 2009). São ligados a ações de persuasão e da comunicação dentro do escopo de ações ligadas à mobilização social. Dentre as características que diferenciam os cartazes políticos de contestação e os de propaganda política de Estado convencionais, podemos destacar a recorrência de um processo de produção coletiva.

Por esse viés, a relação dos designers com os produtos que ajudam a desenvolver não estão desvinculados da responsabilidade pelos conteúdos expostos nos materiais. Não se considera uma dimensão formal separada daquela do artefato em seu uso, que inclui um contexto e uma trama complexa de consequências e apropriações. Rafael Cardoso Denis (1998) aponta que esta característica não é algo contornável.

Ao realizar o ato de projetar, o indivíduo que o faz não somente projeta uma forma ou um objeto mas, necessariamente, também se projeta naquela forma ou naquele objeto. Quero dizer com isto, muito simplesmente, que a coisa projetada reflete a visão de mundo, a consciência do projetista e, portanto, da sociedade e da cultura às quais o projetista pertence. [...] A partir desta constatação histórica, torna-se lícito perguntar: que tipo de cultura material pretendemos legar às gerações futuras como testamento da nossa época e da nossa sociedade? [...] Se for a favor do status quo, cabe-lhe rechear os seus projetos de significados que reforcem, pela continuidade, a tese de que seja este o melhor dos mundos. Se for contra, cabe combater as tendências presentes pela atribuição consciente de significados subversivos ou contestadores. [...] o único papel que o designer não pode se dar ao luxo de exercer é o da omissão e da indiferença (DENIS, 1998,p.37-38). 
Os cartazes de protesto estão inseridos em um circuito que não só são contestatórios em seus conteúdos, como também em seus meios de circulação. Sobre a dinâmica social que permeia a recepção das imagens, cita-se Ana Maria Mauad (2005):

Essa situação varia historicamente, desde o veículo que suporta a imagem até a sua circulação e consumo, passando pelo controle dos meios técnicos de produção cultural, exercido por diferentes grupos que se enfrentam na dinâmica social. Portanto, se a cultura comunica, a ideologia estrutura a comunicação, e a hegemonia social faz com que a imagem da classe dominante predomine, erigindo-se como modelo para as demais (MAUAD, 2005, p.142).

Para Victor Margolin (2000, p.60), "o design como atividade ocorre dentro de um espaço social, e sua contingência particular é definida pelos valores e limites que norteiam um determinado projeto". Entende-se que uma convergência não excludente de estudos históricos e sociais para o debate das questões do design, para além de suas abordagens exclusivamente instrumentais, é fundamental para analisarmos as apropriações de linguagem que discutimos nesse trabalho. Mesmo admitindo-se que os projetos de design se desenvolvem a partir de sistemas técnicos, é necessário ressaltar que eles são estabelecidos na dinâmica social, constituindo nosso cotidiano.

\section{Apropriações e diálogos com outras linguagens}

Além das referências a outras práticas de protesto, como a música, os cartazes comumente se apropriam de imagens e conceitos que circulam na mídia tradicional e estabelecem ligações com outras fontes do repertório iconográfico social.

A apropriação é aqui entendida em uma perspectiva positiva, mesmo reconhecendo o risco de esvaziamento de sentido, ou um "aprisionamento ao passado". Poynor (2010) aponta que em alguns casos a apropriação pode ser positiva e cada caso deve ser analisado em suas especificidades:

\footnotetext{
Essa estratégia de apropriação não apenas gráfica, mas de todo um veículo genérico, pode ser muito produtiva. Permite, em potencial, inter-relações mais complexas, multifacetadas e sugestivas entre o novo conteúdo e o meio gráfico que ele habita. Em vez de simplesmente fazer um pastiche de fragmentos estilísticos, muitas vezes somente para obter um efeito estético nostálgico, abre-se a possibilidade de ressonâncias paródicas mais profundas (POYNOR, 2010, p.93).
}

A organização dos exemplos em itens destaca uma das referências que são mais evidentes, embora seja possível identificar e discutir outras referências na peça gráfica.

\section{Publicidade}

O cartaz "Saia da sombra diga conosco: Liberdade" de 1975 (figura 01a), faz referência à publicidade da Lugolina. O remédio do Dr. Eduardo França era bastante popular no Brasil, comercializado desde 1894. Utilizava em grande parte de seus anúncios impressos rostos de quatro mulheres anunciando cada uma delas as sílabas do nome do remédio com os dizeres no topo "Diga Conosco" ('Diga Comnosco' no anúncio da primeira década do século passado, figura 01b). Percebe-se que a referência é ainda mais cômica quando constatamos que o remédio era originalmente voltado para a prevenção da sífilis, ou um "preservativo das doenças secretas", doença contagiosa que dentre outras consequências, pode afetar o cérebro. 
A composição visual não se sustenta apenas pela referencia do anúncio original, com o desenho das mulheres abrindo as bocas como se falassem o texto. No cartaz do "Movimento feminino pela anistia", as bocas estão escancaradas, como se gritassem. A ideia de sair da sombra é trabalhada com negativos e positivos em diagonal das figuras, inicialmente com as bocas fechadas e finalmente com o texto final no interior das bocas, liberdade.

Figura 01a - Cartaz "Saia da sombra diga conosco", 1975. Figura 01b - Anúncio de Lugolina, [191-].
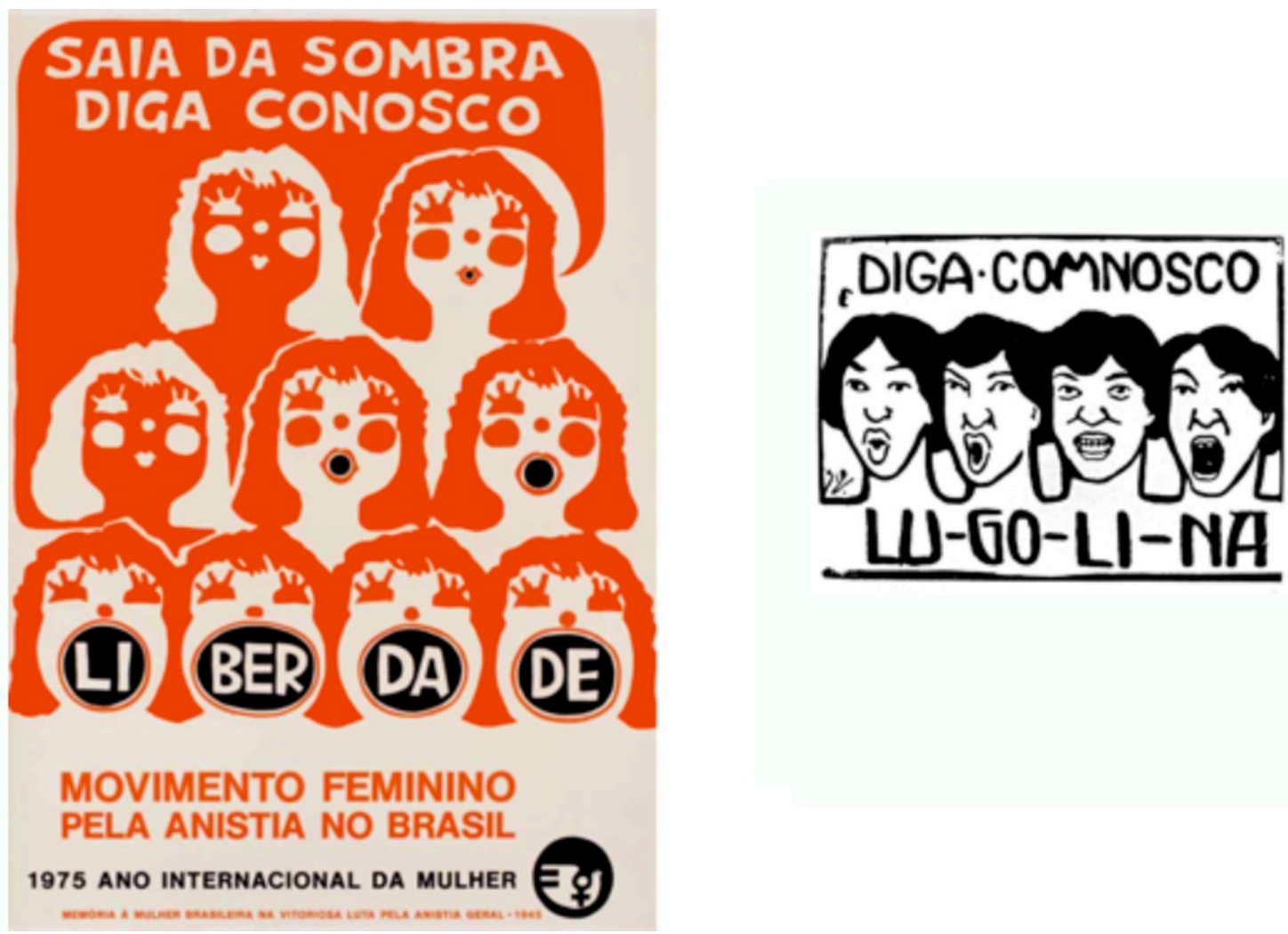

Fonte: Sacchetta (2012, p.76); Fonte: Agência Nacional de Vigilância Sanitária (2008, p.46).

No cartaz, a citação ao movimento político anterior, ocorrido durante o Estado Novo, 30 anos antes, aparece na base da composição, onde se lê: "memória à mulher brasileira na vitoriosa luta pela anistia geral - 1945". Assim, além de rememorar um anúncio publicitário de outra época, evidencia o aspecto histórico da própria mobilização social pela Anistia.

O cartaz "End the bad Breath" (Acabe com o mau hálito) de Seymour Chwast (figura 02a) era ao mesmo tempo uma crítica ao governo intervencionista norte-americano e uma sátira aos slogans da publicidade. Ao invés do "Uncle Sam" de 1917, que solicitava um novo recruta com olhar sério (figura 02b), esse está com olhos arregalados, escancara a boca e feixes saem dele como rastros estilizados de uma explosão.

No lugar dos dentes observamos casas sendo bombardeadas por aviões que rodopiam dentro da boca. O hálito que emanava das bocas desses discursos não era apenas ruim, era destrutivo e nenhum creme dental seria suficiente para contornar o problema. 
Embora o cartaz tenha sido produzido originalmente em 1967, no contexto da guerra do Vietnã, uma reedição com distribuição digital foi realizada em 2004, dessa vez nos protestos contra a guerra do Iraque, comprovando a persistência do tema.

Figura 02a - Cartaz "End Bad Breath" de Seymour Chwast, 2004 (1967).

Figura 02b - Cartaz "I want you for U.S. Army" de James Montgomery Flagg, 1917.

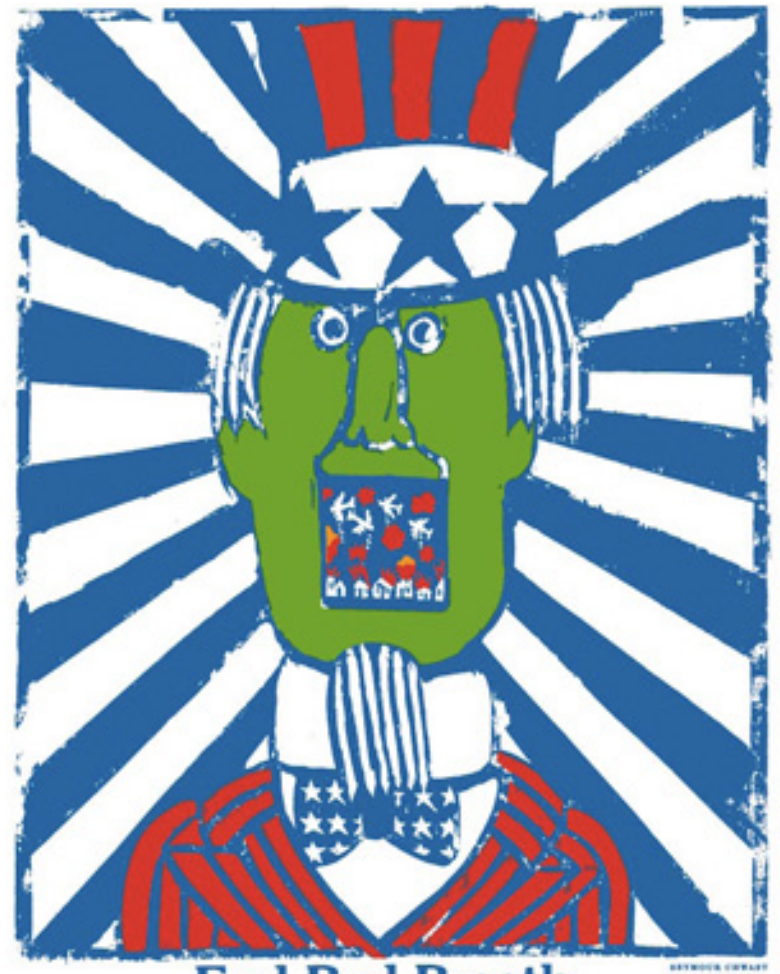

End Bad Breath.

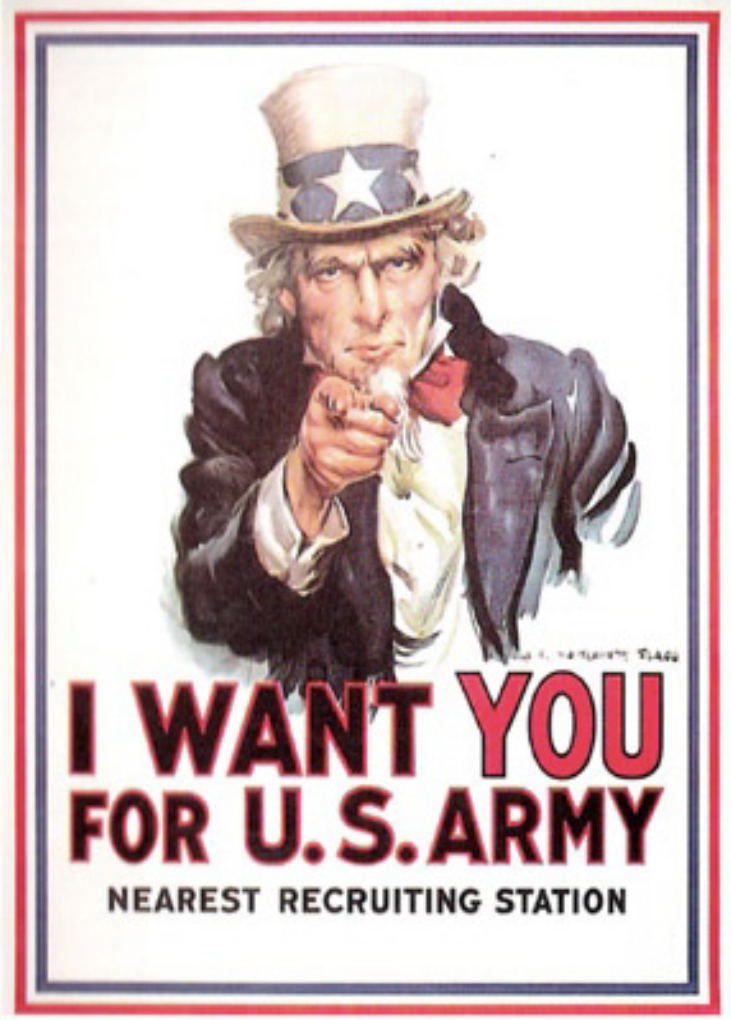

Fonte: anotherposterforpeace.org (2017); Fonte: McQuinston (1993, p.20).

Além da temática propriamente contestatória no âmbito político, a linguagem visual também era experimentada de forma que pode ser considerada crítica àquela vinculada às grandes corporações, à publicidade e à propaganda hegemônica do período em que foi originalmente produzido.

Se considerarmos que nos anos 1950 e 1960 o Estilo Internacional era predominante no discurso oficial do design, com qualidades associadas com o rigor e a precisão (CARDOSO, 2004), é importante destacar que foi nessa mesma época que uma produção bastante influente propunha um caminho bem diferente. Como exemplos desta perspectiva, citamos o escritório "Push Pin Studio" de Nova York, fundado em 1954 por Milton Glaser e o próprio Seymour Chwast, que não tinham receio da ornamentação e da gestualidade. Além disso, desde 1952, Henryk Tomaszewski (1914-2005) da "Escola Polonesa de Cartazes" já lecionava na escola de Belas Artes de Varsóvia, e discutia o caráter contemplativo dos cartazes. Entende-se que ambos os exemplos exigem uma análise crítica em relação ao que seria o ideal nos cartazes, ligados exclusivamente a uma ideia de eficiência e objetividade. 


\section{História em Quadrinhos}

Nos anos 80 eram comuns cartazes que debatiam as questões relativas aos conflitos como os ocorridos na Nicarágua Sandinista (Figura 03) ou ainda aqueles que satirizavam as tragédias decorrentes das alianças políticas e bélicas daquela década (Figura 04). Nos exemplos a seguir, ambos utilizam referências da cultura de massa norte americana como símbolo de sua influência no campo político.

O Super-Homem no cartaz nicaraguense está preso nas mãos de alguém, proporcionalmente muito maior. Na montagem, a mão é uma fotografia, contrastando com o desenho estilizado do super-herói americano. A utilização de fotomontagens, misturando desenhos com fotos, é um recurso bastante conhecido em materiais de contestação, já destacado nas narrativas da história do design, como na produção do alemão John Heartfield (Helmut Herzfeld) desde o início do século XX.

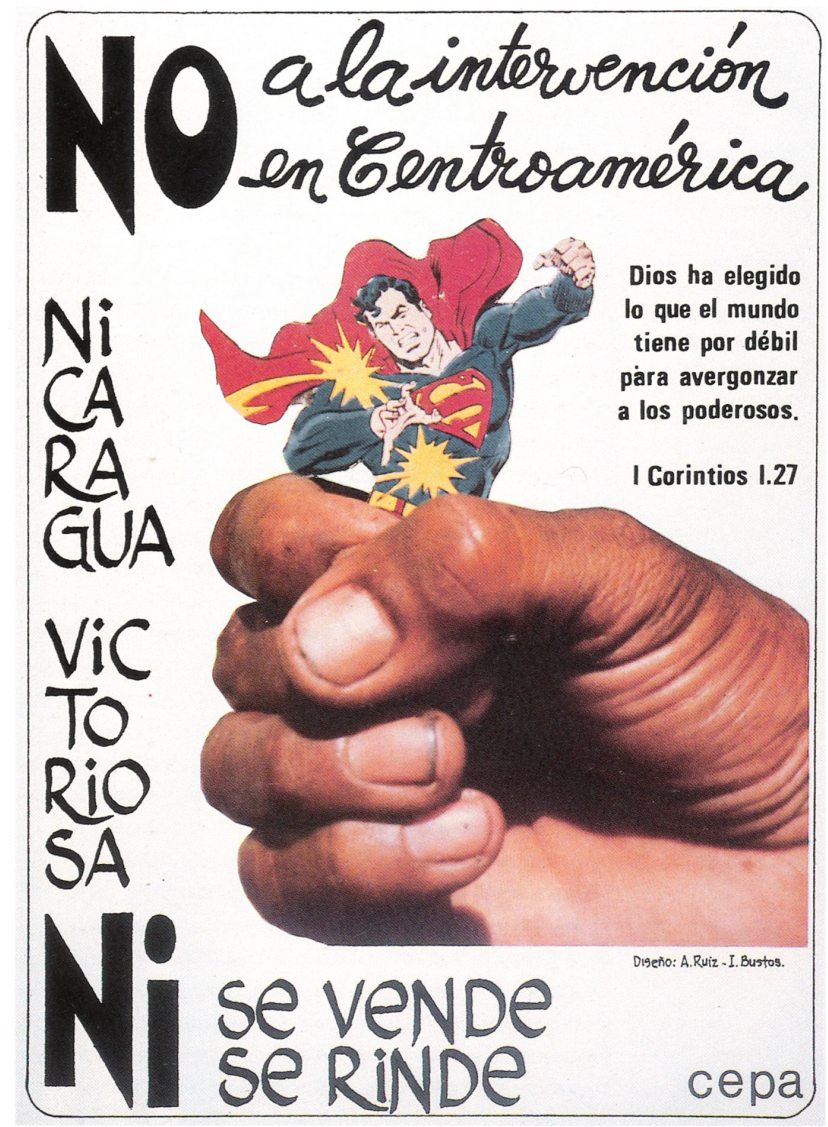

Fonte: McQuinston (1993, p.89).

Considerando-se as convenções da linguagem gráfica das histórias em quadrinhos, observamos que o praticamente invencível personagem está apanhando severamente. Embora não esteja escrito em lugar algum do cartaz, pode-se dizer que o alvo da crítica é certamente os Estados Unidos, que no momento fazia mais uma incursão bélica na Nicarágua. 
De fato, as intervenções norte-americanas no país são uma constante desde pelo menos o século XIX, ou seja desde que a Nicarágua existe como nação independente a partir de 1838. Como exemplos de tais intervenções contam-se o controle das forças armadas, banco central, alfândega, ferrovias e diversos governantes que defendiam diretamente os interesses dos Estados Unidos.

Em 1979 a Nicarágua havia se desvencilhado do governo ditatorial dos Somoza, que durou o período entre o governo de Anastasio Somoza, iniciado em 1936, até a vitória da Frente Sandinista de Libertação Nacional que depôs Anastasio Somoza, filho do anterior. O período imediatamente posterior foi repleto de conflitos, financiados em grande parte pelos Estados Unidos através do fomento declarado dos Contras, milícia vinculada ao governo derrotado em 1979. Nesse interim, durante o governo de Ronald Reagan nos Estados Unidos, ocorreu o escândalo Irã-Contra (1986), quando comprovou-se o desvio de recursos da comercialização de armas americanas para o Irã em favor dos Contras. As inclinações esquerdistas dos Sandinistas foram o argumento para dez anos de recursos encaminhados para a desestabilização do país da América Central.

Os símbolos da cultura de massa atravessam fronteiras nacionais, na mesma medida em que a suposta defesa do ideário que envolve as soberanias nacionais são frágeis diante dos interesses macroeconômicos. O texto do cartaz produzido pelo Centro de Educação e Promoção Agrária daquele país anuncia que "a Nicarágua vitoriosa não se vende nem se rende", novamente evidenciando a percepção de que a violência envolvida na motivação bélica caminha muitas vezes próxima dos interesses financeiros.

\section{Cinema}

O exemplo da Figura 04 faz uma referência ao filme "E o vento levou..." de 1939, filme dirigido por Victor Fleming e produzido por David O. Selznick, assim como a linguagem de cartazes que promovem filmes de maneira geral. A montagem do cartaz britânico substitui Clark Gable por Ronald Reagan e Vivien Leigh por Margareth Thatcher, respectivamente presidente dos Estados Unidos, já mencionado anteriormente e a primeira ministra da Inglaterra em 1984, quando o cartaz foi produzido. $\mathrm{O}$ fato do presidente estadunidense ter sido ator também é relevante para $\mathrm{o}$ caráter tragicômico da mensagem.

A história de Scarlett O'Hara e seus descaminhos amorosos e financeiros durante a Guerra Civil Americana é deixada de lado em favor de uma discussão que abrange o mundo todo, reforçado pelo texto na base do cartaz (now showing world wide). As chamas de Atlanta também são substituídas, desta vez por um cogumelo atômico, apresentando uma paisagem sempre iminente no imaginário da década de 1980.

A paleta de cores se resume às cores vermelha, azul e branca, que as bandeiras dos Estados Unidos e Inglaterra compartilham. A tipografia segue os padrões estilísticos do filme original de 1939. A imagem foi originalmente produzida para a quarta capa do periódico britânico "The Socialist Worker", posteriormente adaptado para outros formatos, maiores como para o cartaz e menores para cartões postais.

No canto inferior esquerdo lemos que o filme é uma produção do $\mathrm{FMI}$, o realizador, apontado logo acima do título do "filme", é o economista Milton Friedman, um dos principais defensores do livre-mercado no período, em associação com o Pentágono. O slogan do filme é “o 
filme que vai acabar com todos os filmes" (the film to end all films). Não se trata apenas de uma crítica às campanhas bélicas que envolviam esses países, mas também uma crítica às políticas econômicas do período e seus efeitos.

Figura 04 - Cartaz Gone with the wind. Margareth Thatcher aos braços de Ronald Reagan na montagem dos ingleses Bob Light e John Houston, 1984.

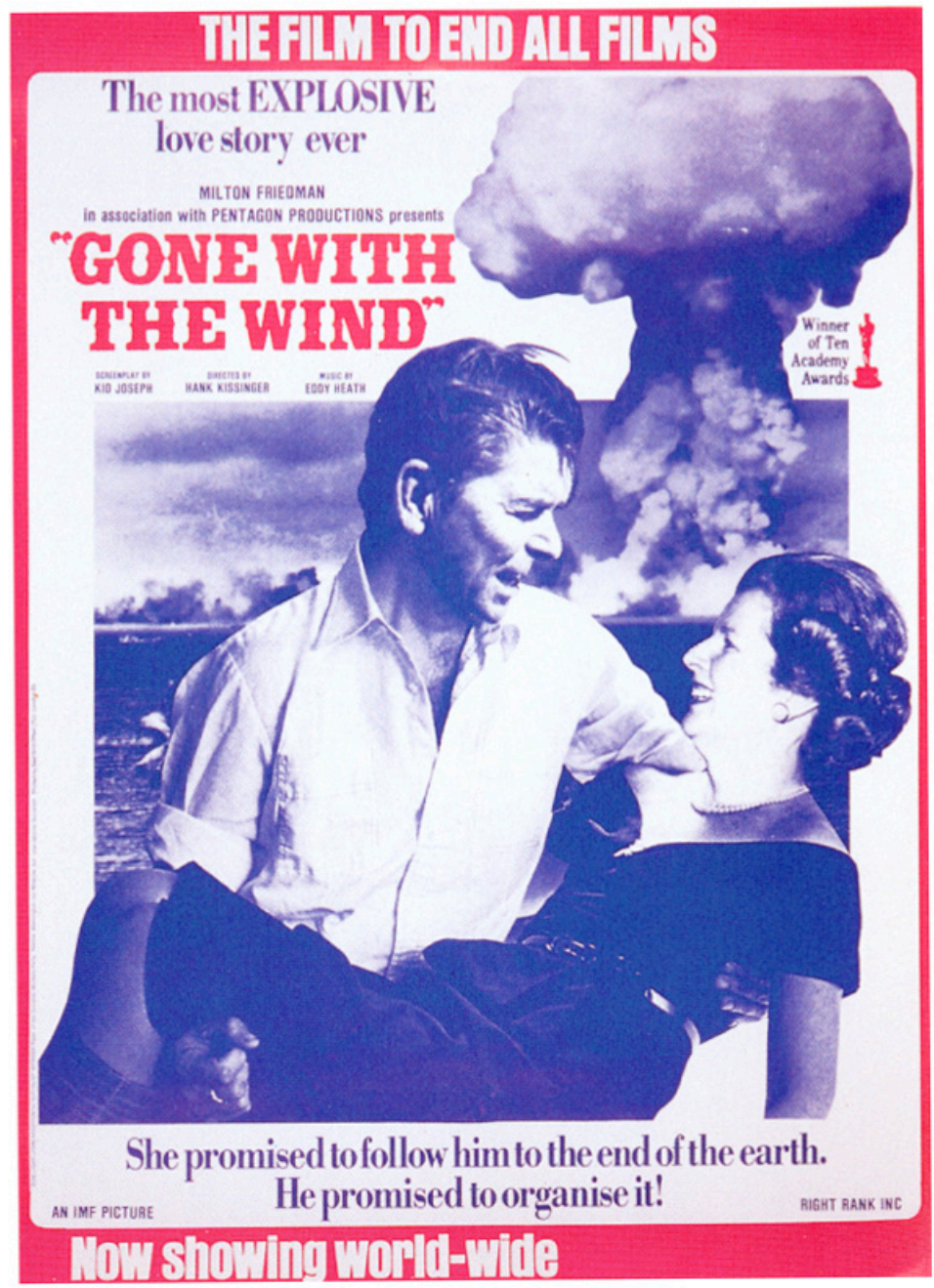

Fonte: McQuinston (1993, p.100).

\section{Fotojornalismo}

Na Ásia, em um exemplo mais recente, podemos citar o cartaz do chinês Badiucao (Figura 05), associando os eventos de mobilização em Hong Kong a partir de setembro de 2014 a favor de uma condução política democrática, o movimento conhecido como "Umbrella Revolution" ou "Occupy Central Movement", com a famosa manifestação de resistência registrada em fotos e por filmagens na Praça Tiananmen (Paz Celestial) em Pequim.

$\mathrm{Na}$ ocasião da foto na capital chinesa, 05 de junho de 1989, Hong Kong ainda era administrado como Colônia Britânica. Assim, esse cartaz faz uma ligação entre o evento em prol da democracia daquele ano com os movimentos mais recentes, destacando a atual condição de Região Administrativa Especial Chinesa de Hong Kong. "Umbrella Revolution" se refere aos 
guarda-chuvas manuseados pelos manifestantes para se proteger do gás lacrimogêneo e spray de pimenta utilizado pela repressão das manifestações (Mcquiston, 2015, p.98).

Figura 05 - Cartaz 1989-2014 de Badiucao, 2014.

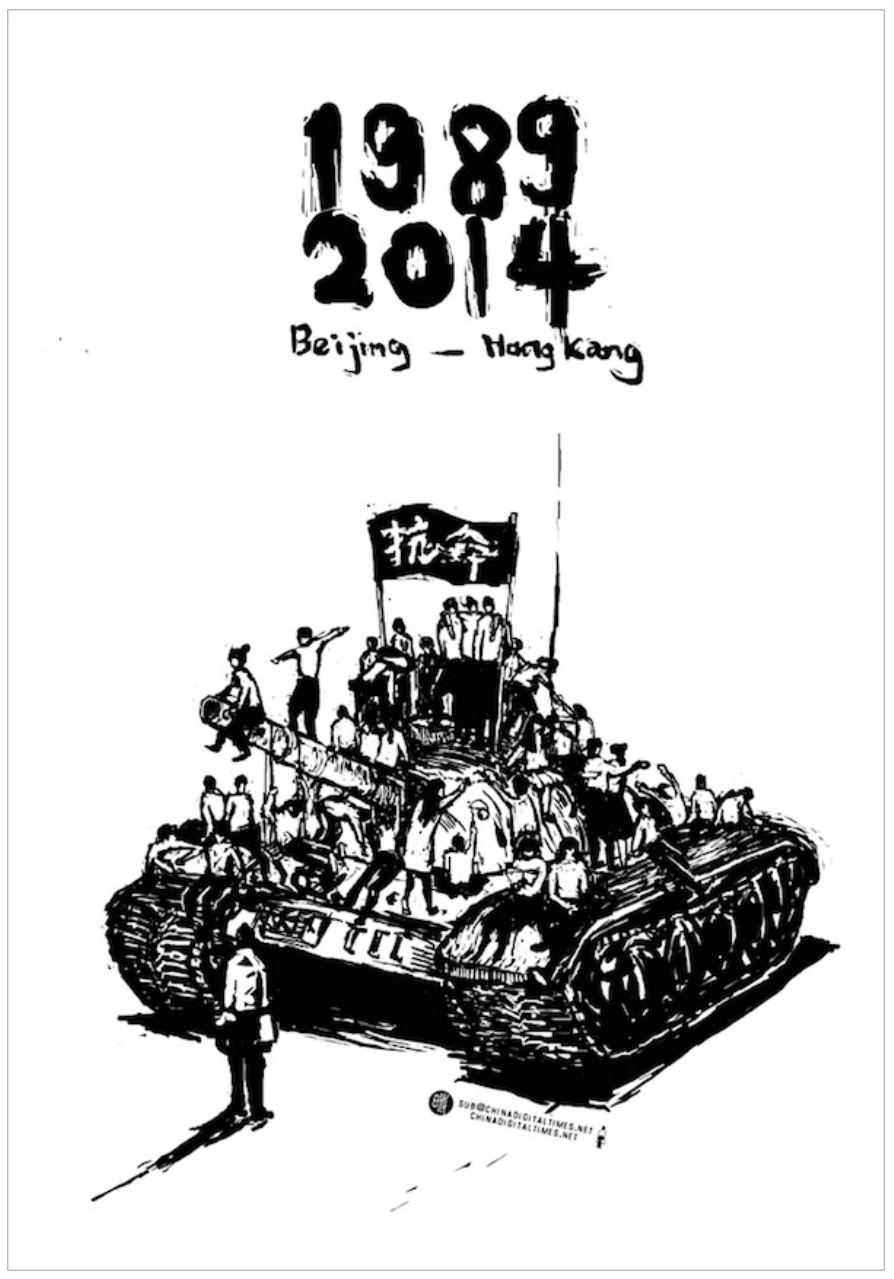

Fonte: http://chinadigitaltimes.net/2014/09/

Nesse exemplo os manifestantes ocupam também o tanque, de forma que o protesto solitário anterior, do "rebelde desconhecido", é desta vez acompanhado por um grande grupo. Estes carregam uma bandeira escrito (抗命 / kangmin / desobediência), palavra bastante utilizada nas manifestações, se referindo à desobediência civil e também ao fragilizado direito de protesto.

Badiucao é um artista e cartunista político chinês, nascido em Shangai, mas que mora na Austrália. Ele não revela seu nome verdadeiro por questões de segurança. O cartaz foi feito para a o jornal China Digital Times, onde é colaborador.

\section{Música e a história do design de contestação}

A imagem do policial prestes a espancar alguém do cartaz do Atelier Populaire (figura 06b) é apropriada e somada a outras referências (figura 06a), como as letras "SS" da Schutzstaffel e nessa versão fotografada ainda cita trechos da letra "Acorda Amor", famosa música de Chico Buarque de 1974, que originalmente se referia à repressão durante o período da ditadura militar 
no Brasil. Altera, no entanto, a frase "sonhei que tinha gente lá fora" por "sonhei que repetia a história". No contexto do cartaz o pastiche se justifica pela última frase: trata-se de remeter a diversos períodos históricos e países, a Alemanha Nazista, a França dos movimentos de 68, o Brasil da ditadura e a ideia de repetição no contexto brasileiro de 2016.

O cartaz foi fotografado na Avenida Paulista, em São Paulo em 2016. Seu formato, um A4, assim como a qualidade de impressão, aparentemente utilizando uma fotocopiadora, sugerem uma produção de pequena tiragem ou mesmo doméstica. A composição visual e aspetos como a legibilidade não refletem a simplicidade e objetividade do cartaz original, mas outros aspectos, como o caráter contestatório e de engajamento.

Figura 06a - Cartaz fotografado na Avenida Paulista em São Paulo; Figura 06b - Cartaz do Atelier Populaire de 1968.
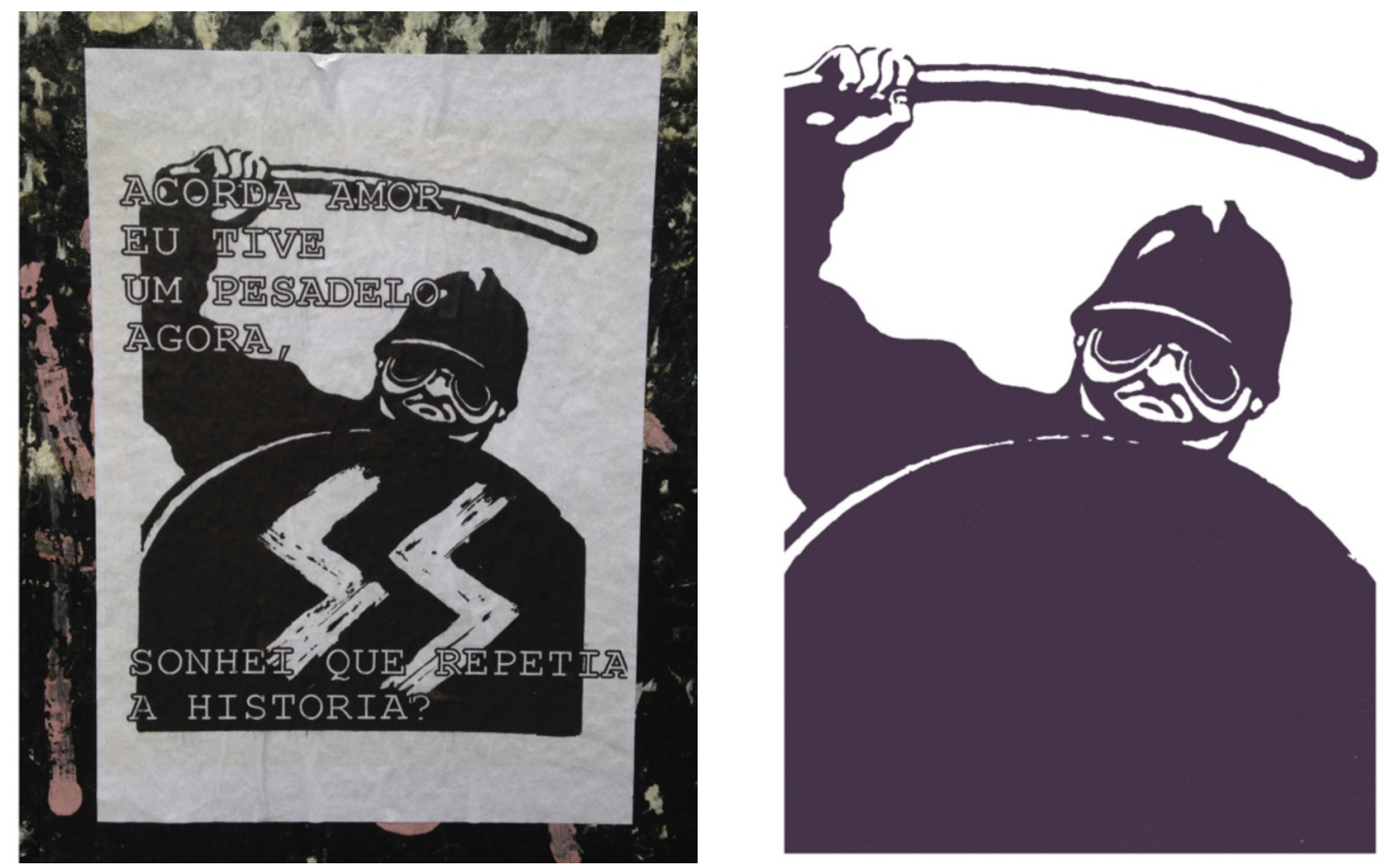

Fonte: Foto do autor, 2016; Fonte: McQuinston (1993, p.55).

Os trabalhos do Atelier Populaire, realizados durante os eventos de maio de 1968 na França, estão entre os mais citados nos textos que descrevem a produção de cartazes de protesto. Segundo Liz McQuinston (1993, p.54-55), a experiência de produzir materiais gráficos envolvendo trabalhadores de diversos setores e estudantes foi bastante particular. A urgência com que eram desenvolvidos assim como outras limitações técnicas, influenciaram diretamente nas soluções visuais que adotaram para os cartazes.

Embora alguns dos membros envolvidos tenham permanecido no campo do design gráfico, o atelier em si foi uma experiência breve. O início das atividades ocorreu a partir do dia 14 de maio de 1968, quando estudantes ocuparam as oficinas de gravura da Escola de Belas Artes da Universidade de Paris e ficaram lá por 50 dias, até 27 de junho, quando foram retirados pela polícia.

O Atelier Populaire se organizava como uma mobilização social, unidos por causas em 
comum, tais como uma nova perspectiva na educação e melhores condições de trabalho. As assembleias nas oficinas não tratavam apenas de elaborar o visual do cartaz, mas também realizar a discussão política dos temas a serem abordados. A produção desses cartazes tornou-se referência importante no que diz respeito às suas soluções visuais, além da discussão promovida pelas técnicas de criação através da ação direta. Ou ainda, segundo Chico Homem de Melo (2006, p.32): "O sonho de uma sociedade igualitária manifestava-se portanto nas próprias condições de produção do design".

Bárbara Szaniecki (2007) escreve sobre o assunto:

\begin{abstract}
A produção do Atelier Populaire é realizada de forma coletiva e democrática, radicalmente horizontal, e destina-se a toda a sociedade, isto é, aos estudantes e seus professores, aos trabalhadores e seus patrões, aos cidadãos e seus dirigentes. A indefinição dos planos e a fusão das formas refletem seu anseio pela ausência de hierarquia na produção. (SZANIECKI, 2007, p.84)
\end{abstract}

A linguagem visual bastante simples, geralmente impressa utilizando apenas uma cor, com letras desenhadas e silhuetas, além de estar relacionada com as limitações técnicas da serigrafia, também tinha um efeito visual que remetia à ideia de contestação, na medida em que contrastavam com a publicidade colorida e de imagens fotográficas.

\title{
4 Considerações
}

Além de destacar as aproximações com personagens, música e referências de diversos meios de comunicação, os cartazes nesse artigo são apresentados de maneira que seus contextos são brevemente descritos. Argumenta-se que dessa maneira, as apropriações podem ser interpretadas para além de seus aspectos formais/plásticos e assim apresentar, em cada caso particular, uma possibilidade de análise crítica mais complexa do uso desse recurso.

Ressalta-se que aspectos mais específicos dos usos desses cartazes, tais como os espaços específicos onde foram originalmente utilizados, as pessoas envolvidas na produção e distribuição desses cartazes no período em que eles foram originalmente expostos, poderiam indicar novas interpretações para estes materiais.

Os cartazes apresentados ilustram a dificuldade envolvida na separação disciplinar que não parece condizer com a complexidade exigida no desenvolvimento de projetos e apontam para a necessidade da ampliação e aprofundamento das questões sociológicas, culturais e de linguagem dentro do escopo dos estudos e práticas em design. As análises das apropriações de linguagem exigem, pelo viés escolhido, uma pesquisa de abordagem interdisciplinar.

Ao encararmos o design gráfico também como uma forma de ação comunicativa crítica, podemos evidenciar novas metodologias de projeto e a investigação de soluções de produção e linguagem.

\section{Referências}

AGÊNCIA NACIONAL DE VIGILÂNCIA SANITÁRIA. Vendendo Saúde: história da propaganda de medicamentos no Brasil. Brasília: Agência Nacional de Vigilância Sanitária, 2008. Disponível em <http://www.anvisa.gov.br/propaganda/vendendo_saude.pdf> Acesso em: 26 de julho de 2017. 
BARNICOAT, John. Los carteles. Su historia e lenguaje. Barcelona: Gustavo Gile, 1972.

CARDOSO, Rafael. Uma introdução à história do design. São Paulo: Blücher, 2004.

DENIS, Rafael Cardoso. Design, cultura material e o fetichismo dos objetos. In: ARCOS. Design, cultura material e visualidade. Volume I. Rio de Janeiro: Contra Capa, 1998, p. 14-39.

HOLLIS, Richard. Design gráfico. Uma história concisa. São Paulo: Martins Fontes, 2001.

MARGOLIN, Victor. Os dois Herbert: história, teoria e crítica no ensino de design em nível de doutorado. In: ARCOS. Design, cultura material e visualidade. Volume III. Rio de Janeiro: Contra Capa; Programa de Pós Graduação em Design / ESDI, 2000, p. 48-63.

MAUAD, Ana Maria. Na mira do olhar: um exercício de análise da fotografia nas revistas ilustradas cariocas, na primeira metade do século XX. Anais do Museu Paulista. São Paulo. v.13. n.1. p. 133174. jan. - jun. 2005. Disponível em: < http://www.revistas.usp.br/anaismp/article/view/5417/ 6947>. Acesso em 13 de fevereiro de 2018.

McQUINSTON, Liz. Graphic Agitation. Social and political graphics since the sixties. London: Phaidon Press, 1993.

2004.

Graphic Agitation 2. Social and political graphics in the digital age. London: Phaidon Press,

. Visual impact. Creative dissent in the 21st century. London: Phaidon Press, 2015.

MEGGS, P. B. História do Design gráfico. São Paulo: Cosac Naify, 2009.

MELO, Chico Homem de. (org.). O design gráfico brasileiro: anos 60. São Paulo: Cosac Naify, 2006. POYNOR, Rick. Abaixo as regras. Porto Alegre: Bookman, 2010.

SACCHETTA, Vladimir (org.). Os cartazes dessa história. São Paulo: Instituto Herzog; Escrituras, 2012.

SZANIECKI, Barbara. Estética da multidão. Rio de Janeiro: Civilização Brasileira, 2007. 